\title{
Commercial interests, transparency, and independence: a call for submissions
}

\author{
Help the move towards independence from commercial interests
}

\author{
Ray Moynihan assistant professor ${ }^{1}$, Helen Macdonald UK research editor ${ }^{2}$, Carl Heneghan professor, \\ Lisa Bero professor ${ }^{4}$, Fiona Godlee editor in chief $^{2}$
}

${ }^{1}$ Centre for Research in Evidence-Based Practice, Bond University, Gold Coast, Australia; ${ }^{2}$ The BMJ, London, UK; ${ }^{3}$ Nuffield Department of Primary Care, Oxford University, Oxford, UK; ${ }^{4}$ Charles Perkins Centre, University of Sydney, Sydney, Australia

\begin{abstract}
A decade ago the US Institute of Medicine (IOM) issued a landmark report on conflicts of interest in research, medical education, and practice. ${ }^{1}$ Highlighting benefits of collaborations between physicians, researchers, and companies to develop new products that can improve health, the report also raised substantial concerns that extensive financial ties could unduly influence professional judgments. It concluded these financial conflicts of interest could jeopardise the integrity of science, the objectivity of education, the quality of care, and public trust in medicine. The report recommended more research on conflicts of interest, improvements in transparency, and greater independence from industry.
\end{abstract}

Today we announce plans for a stream of BMJ content to revisit these concerns and ask you to join us. A key aim is to identify and respond to commercial influences on health and healthcare, to understand under what circumstances involvement with industry is truly necessary. Where it is not necessary, we want to forge a new independence from those who make and sell products, to strengthen trust in how evidence is produced and disseminated, and to drive more rational and safer use of drugs, devices, diagnoses, and data in the public interest.

\section{Problematic relationships}

Since the 2009 IOM report, transparency has improved, but key recommended steps towards independence—-such as prohibiting free meals, excluding conflicted authors from guidelines, and ending industry influenced medical education-have not been taken. These practices are still widespread despite continuing evidence of distorting impacts on research and practice. A 2010 cross sectional review found that the views of "key opinion leaders" strongly correlate with their sponsor's interests. ${ }^{2}$ A 2016 study of 279000 physicians, using the new US Open Payments transparency initiative (https://www.cms.gov/ openpayments/), found an association between receipt of just one promotional meal and higher prescriptions of the sponsors' drugs. ${ }^{3}$ A 2017 Cochrane review has confirmed that sponsored clinical trials tend to find more favourable outcomes about sponsors' products. ${ }^{4}$ In 2018 new evidence has identified ongoing sponsor involvement in design conduct and reporting of research, and a lack of transparency around such involvement. ${ }^{5}$

Other work shows how companies can control information about their products by selectively publishing or suppressing data and even by changing the standards used to evaluate research, ${ }^{6}$ as described in figure 1. Investigative journalism continues to expose cases where financial interests have contributed to patient harm, as occurred with diabetes drug rosiglitazone, ${ }^{7}$ with infant formula, ${ }^{8}$ and with vaginal mesh. ${ }^{9}$ These examples bear witness to inadequate regulation, aggressive marketing, and a research establishment and medical profession still firmly entangled with industry.

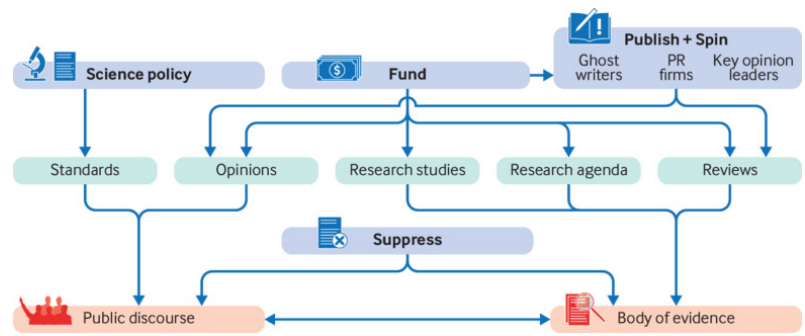

Industry strategies to influence evidence and discourse about evidence

The past decade has seen a growing and related understanding of the threat to human health from overdiagnosis and too much medicine (https://www.bmj.com/too-much-medicine). Recent research confirms the extent to which this medical excess is driven by commercial influences, including on disease definitions. ${ }^{10}$ By failing to mitigate these influences we overmedicalise society by labelling healthy people as sick, causing unnecessary cost to health systems and harm to patients. 


\section{The BMJ's response so far}

The 2009 IOM report described transparency as a "critical but limited first step in the process of identifying and responding to conflicts of interest." It suggested that if medical organisations did not act to reduce conflicts then pressure would likely mount for external regulation. Taking up this challenge, The BMJ has updated its policies around ties with commercial companies (box 1).

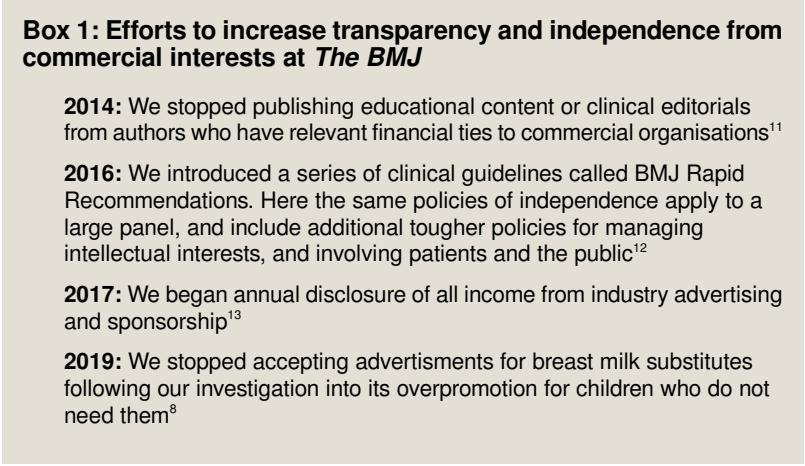

These changes show that The $B M J$ aims not only to describe the, problem but to be part of the solution. They have led to difficult conversations, harder work, increased costs, or loss of revenue. Other organisations will have considered or taken similar steps. We would like to hear about these discussions and reforms, and where possible, outcomes and impact. We also welcome your thoughts on what we should focus on next.

The BMJ has also worked with the Centre for Evidence Based Medicine at Oxford University and a global community of evidence based medicine supporters to frame a manifesto for better evidence in medicine. ${ }^{14}$ One of the manifesto's nine commitments is to reduce conflicts of interest to facilitate better creation, translation, and use of evidence. Our jointly hosted conference, EBM Live, will include a themed day on conflicts of interest in July 2019.

We recognise that taking a strong stance on commercial interests is just one piece of a wider picture of other financial and also non-financial interests. There are many differing perspectives, including from those who question assumptions about the dangers of conflicts of interest. ${ }^{15}$ By focusing on commercial financial interests we do not aim to minimise or avoid this wider discussion.

\section{Call for submissions}

Today, The BMJ launches a call for submissions for a themed collection (box 2). New transparency initiatives such as US Open Payments provide invaluable data, and we welcome research drawing on these new sources. There are also new and important relationships to study: those with commercial entities beyond drug companies, and those between industry and patient and consumer advocacy groups, which are rightly increasingly influential in the creation and use of evidence.
Box 2: Call for submissions to The BMJ themed collection on commercial interests, transparency, independence

Aims of the collection

- To better understand the nature of commercial conflicts of interest

- To examine how commercial interests affect health and healthcare, including health research, practice, and education

- To explore when commercial ties are truly necessary and when independence is most needed

- To share examples of progress from transparency to independence

\section{What are we looking for?}

- Submissions for the themed collection are open across all article formats for The BMJ. We seek original data, qualitative and quantitative analysis, as well as evaluated examples of groups or organisations forging genuine independence from industry

- We are particularly interested in submissions about industry's involvement in evidence creation, evaluation, synthesis and translation into guidelines, and about moves towards independence in these processes

- We welcome submissions about the interests of commercial organisations producing any products that affect health, including drugs, devices, food, drink, insurance, social media, and information technology

- We welcome exploration of ties between industry and all groups relevant to health, including healthcare professional, researchers, and patient or consumer advocacy groups

We may offer publication of selected research articles in our sister journal BMJ Open rather than The BMJ, with an online link to the collection. Submissions are welcome from now, with a final deadline of 15 January 2020. Normal publication processes for each journal will apply. For feedback on ideas before submission please contact hmacdonald@bmj.com

We intend to launch initial material at the Preventing Overdiagnosis conference in Sydney on 5-7 December 2019 (www.preventingoverdiagnosis.net) and the full collection at EBM Live in July 2020 (ebmlive.org). We look forward to receiving your work.

This article has been reposted to correct a grammatical erro

We thank Meng Koach for the figure.

Competing interests: We have read and understood BMJ policy on declaration of interests and declare the following interests: RM is funded by a National Health and Medical Research Council fellowship, GNT1124207, and hosts a podcast funded by Cochrane Australia. The idea for this collection of content was suggested by RM and adapted in collaboration with the listed authors. FG and HM are editors of The $B M J$, which is committed to increasing transparency and ensuring that evidence and practice are independent from financial interests. The BMJ receives income from commercial advertisers and sponsors, declared annually at https:// www.bmj.com/about-bmj/publishing-model. RM has a longstanding interest in conflicts of interest, enhanced transparency, and more independence from commercial interests in healthcare and is cochair of the Preventing Overdiagnosis scientific committee. $\mathrm{CH}$ has received expenses and fees for his media work, and he holds grant funding from the NIHR, the NIHR School of Primary Care Research and The NIHR Oxford BRC. CH is Editor in Chief of BMJ Evidence-Based Medicine, an NHS urgent care GP and Director of CEBM, which jointly runs the EvidenceLive Conference with the BMJ and the Overdiagnosis Conference with international partners based on a non-profit model. RM and LB are guest editors of the BMJ themed collection on commercial interests.

Provenance and peer review: Commissioned; not externally peer reviewed.

Lo B, Field MJ. Conflict of interest in medical research, education, and practice. National Academies Press, 2009

2 Wang AT, McCoy CP, Murad MH, Montori VM. Association between industry affiliation and position on cardiovascular risk with rosiglitazone: cross sectional systematic review. BMJ 2010:340:c1344 10.1136/bmi.c1344 20299696

3 DeJong C, Aguilar T, Tseng CW, Lin GA, Boscardin WJ, Dudley RA. Pharmaceutical industry-sponsored meals and physician prescribing patterns for Medicare beneficiaries. JAMA Intern Med 2016;176:1114-22. 10.1001/jamainternmed.2016.2765 27322350

4 Lundh A, Lexchin J, Mintzes B, Schroll JB, Bero L. Industry sponsorship and research outcome. Cochrane Database Syst Rev 2017;2:MR000033.28207928

5 Rochon PA, Stall NM, Savage RD, Chan AW. Transparency in clinical trial reporting. BMJ 2018:363:k4224. 10.1136/bmj.k4224 30301724 
$6 \quad$ Bero L. Ten tips for spotting industry involvement in science policy. Tob Control 2018;28:1-2.29941543

7 Cohen D. Rosiglitazone: what went wrong?BMJ 2010;341:c4848. 10.1136/bmj.c4848 20819889

8 Godlee F. Disentangling ourselves from "big formula."BMJ 2018;363:k514610.1136/bmj.k5146 .

9 Heneghan C, Aronson JK, Goldacre B, Mahtani KR, Plüddemann A, Onakpoya I. Transvaginal mesh failure: lessons for regulation of implantable devices. BMJ 2017;359:j5515. 10.1136/bmi.j5515 29217786

10 Pathirana T, Clark J, Moynihan R. Mapping the drivers of overdiagnosis to potential solutions. BMJ 2017;358:j3879. 10.1136/bmj.j3879 28814436

11 Chew M, Brizzell C, Abbasi K, Godlee F. Medical journals and industry ties. BMJ 2014;349:g7197. 10.1136/bmj.g7197 25432164
12 Siemieniuk RA, Agoritsas T, Macdonald H, Guyatt GH, Brandt L, Vandvik PO. Introduction to BMJ Rapid Recommendations. BMJ 2016;354:5191. 10.1136/bmj.i5191 27680768

13 Godlee F, Abbasi K, Bloom T. BMJ declares its revenues from industry. BMJ 2017;359:j4930. 10.1136/bmj.j4930 29070599

14 Heneghan C, Mahtani KR, Goldacre B, Godlee F, Macdonald H, Jarvies D. Evidence based medicine manifesto for better healthcare. BMJ 2017;357:j2973. $10.1136 / \mathrm{bmj} . j 297328634227$

15 Rosenbaum L. Conflicts of interest: part 1: reconnecting the dots-reinterpreting industry-physician relations. N Engl J Med 2015;372:1860-4. 10.1056/NEJMms150249325946288

Published by the BMJ Publishing Group Limited. For permission to use (where not already granted under a licence) please go to http://group.bmj.com/group/rights-licensing/ permissions 